\title{
Ocean-atmosphere coupling and short term fluctuations of earth rotation
}

Ocean-atmosphere coupling Fluctuations Earth rotation

Couplage océan-atmosphère Fluctuations Rotation terrestre

\section{J. A. GONELLA \\ Muséum National d'Histoire Naturelle, 43-45, rue Cuvier, 75005 Paris, France.}

Received $10 / 10 / 8^{*}$, in revised form $8 / 9 / 86$, accepted $11 / 9 / 86$,

ABSTRACT
Sr eral authors have shown that measurements of fluctuations in length-of-day (1.o.d.) and angular momentum of the atmosphere are strongly correlated; these measurements support the ass' nption that the entire planet is a closed dynamic system. Accelerations of angular momentum of the atmosphere occur simultaneously with decelerations of the rotation of the solid earth, and vice versa, with 1.o.d. change of about one millisecond in an annual period. In this paper, only the minor role of the world ocean is discussed. The ${ }^{r}$ uthern Ocean, which is wind-driven, could make, at the most, a cuntribution of only a few percent of the total change of 1.o.d. In the oceans, phase velocities of barotropic waves range between 2000 to $20000 \mathrm{~km} /$ day; these large free oceanic waves could act on l.o.d. changes only in the frequency band ranging from 0.1 to 1 cycle per day. On the annual and seasonal scales, it is emphasized that the global water balance, within the water cycle (evaporation, condensation, precipitation), could have a 1 . , er effect than oceanic circulation on earth-rotation. In the future, more attention must be focused on the influence of the latitudinal exchange of water substance between ocean, atmosphere and continents (ice sheets included) on 1.o.d. changes.

Oceanol. Acta, 1987, 10, 1, 123-127.

\section{RÉSUMÉ}

Couplage océan-atmosphère et fluctuations de courte période de la rotation terrestre

Plusieurs auteurs ont montré la forte corrélation existant entre les fluctuations de la vitesse de la rotation terrestre et le moment cinétique de l'atmosphère par rapport à l'axe des pôles (moment angulaire). Bien que le processus de transfert ne soit pas encore compris, l'amplitude et la cohérence de ces mesures justifient l'hypothèse que la planète, c'est-à-dire la terre solide et son atmosphère, constitue un système dynamique fermé. Toute accélération du moment angulaire de l'atmosphère se traduit par une décélération correspondante de la rotation de la terre solide et vice versa, avec une amplitude de l'oscillation de la durée du jour de l'ordre de $\pm 0,5$ milliseconde par an. Dans cet article, nous examinons le rôle possible de l'océan mondial. Seul l'Océan Austral (ou Antarctique) dont la circulation circumpolaire est essentiellement entretenue par le vent, pourrait expliquer quelques pourcent de l'amplitude des fluctuations de la durée du jour. Dans les océans, les vitesses de phase des ondes barotropes varient de 2000 à $20000 \mathrm{~km}$ par jour; la propagation de ces ondes longues ne peut induire des perturbations des paramètres de la rotation terrestre que dans le domaine de fréquence allant de 0,1 à 1 cycle par jour. Aux échelles saisonnières et annuelles, l'influence des fluctuations du bilan hydrique global (évaporation, condensation, précipitation) ne peut être négligée. Leurs effets sur la rotation terrestre pourraient être plus importants que ceux liés aux variations de la circulation océanique. Dans le futur, une plus grande attention devrait être portée à l'étude du cycle de l'eau (notamment les flux méridiens) à l'échelle de la planète pour mieux comprendre les fluctuations de la longueur du jour.

Oceanol. Acta, 1987, 10, 1, 123-127. 


\section{INTRODUCTION}

How does the ocean-atmosphere coupling can act on earth-rotation parameters? This interesting question still remains unsolved. Interactions between ocean and atmosphere are complex but, a priori, the two major phenomena which can have some effects are:

- mechanical input from the atmosphere to the ocean by wind-stress (momentum transfer) and by atmospheric pressure; both act on the dynamics of the ocean and on its angular momentum;

- water mass exchange through the fluctuating cycle: excess of evaporation from oceans, condensation in the atmosphere, excess of precipitation on continents and ice sheets; this cycle has a direct influence on the moment of inertia of the earth and consequently on the variation of the length-of-day (1.o.d.).

Oceanic current data are not yet available on a global scale and oceanic angular momentum cannot be computed as accurately as the atmospheric one (Barnes et al., 1983; Rosen, Salstein, 1983 and 1985). Nevertheless the understanding of ocean dynamics could permit us to appreciate its possible effect on earth rotation. Any kind of forcing on the world ocean (tidal forces, atmospheric pressure, wind stress, earthquake...) generates oceanic waves which propagate kinetit and potential energy. Only large oceanic gravity waves (i.e. tides, Kelvin waves...) and planetary waves (also called Rossby waves) may have some influence on earthrotation parameters.

This paper is composed as follows. First, a short comparison is made between the magnitude of the atmospheric and oceanic mean angular momenta. There follows a brief description of the characteristics of long free oceanic waves and the frequency range on which they could affect the earth-rotation parameters. Because the ocean-atmosphere coupling is not only dynamic, the thermodynamic effect will be explored on a global scale in terms of water mass exchange within the cycle: evaporation, condensation, precipitation.

The discussion will focus attention on the role of the global water balance on annual and seasonal variations of the earth-rotation parameters.

\section{OCEANIC AND ATMOSPHERIC ANGULAR MOMENTA: THE SOUTHERN OCEAN ZONAL FLUX}

It is well known that an order of magnitude exists between atmospheric (Ma) and oceanic (Mo) angular momenta (Munk, MacDonald, 1960; Lambeck, 1980). The ratio of these angular momenta $(\mathrm{Mo} / \mathrm{Ma})$ is the product of the ratios of the masses $(\mathrm{mo} / \mathrm{ma})$ and mean velocities (vo/va) modulated by the percentage of free zonal circulation for both fluids all around the globe.

The mass ratio can be estimated by the ratio of mean depth of oceans on a globe without continents $(2500 \mathrm{~m})$ by the equivalent water height of the atmospheric pressure $(10 \mathrm{~m})$. In the oceans, the averaged value of cur- rents from surface to bottom is of the order of $1 \mathrm{~cm} / \mathrm{s}$; in the atmosphere, the average wind velocity is around $10 \mathrm{~m} / \mathrm{s}(1000 \mathrm{~cm} / \mathrm{s})$. Furthermore the atmosphere can circulate freely all around the globe; of the oceans, only the Southern one $(16 \%$ of the earth surface; $25 \%$ of the ocean volume) has a free zonal circulation; we will take a compromise at $20 \%$ for the computation. Because of the fluid continuity equation, the angular momentum for the other oceans with meridional boundaries can be neglected. All these estimates may be summarized:

- mass ratio: $\mathrm{mo} / \mathrm{ma}=2500 / 10=250$;

- velocity ratio: vo/va $=1 / 1000=10^{-3}$;

- zonal circulation ratio: $\% / \% / \% a=20 / 100=0.2$;

- angular momemum ratio:

$\mathrm{Mo} / \mathrm{Ma}=250 \times 10^{-3} \times 0.2=5 \times 10^{-2}$.

The oceanic angular momentum amounts to only a few percent of the atmospheric one. This rough approximation represents an upper limit in agreement with results from previous works (Eubanks, 1985). More recently, Rosen and Salstein (1985) conclude that "there seems little need to invoke processes other than atmospheric motions to explain seasonal, nontidal changes in 1.o.d."; in other words, that the zonal oceanic flux has no effect at all on l.o.d. changes!

Nevertheless, in a closed system, if the mean westerly value of $\mathrm{Ma}=1.4 \times 10^{26} \mathrm{~kg} \cdot \mathrm{m}^{2} / \mathrm{s}$ (Rosen, Salstein, 1983) was transferred to the solid earth, the length of day would be shortened by 2.3 milliseconds. On the other hand, if we consider the values measured by different authors for the Antarctic Circumpolar Current (AACC) flux, we have:

- through the Drake Passage: 124 SV (Sverdrups) by Nowlin, Whitworth and Pillsbury (1977), value revised more accurately to $123( \pm \mathrm{rms}=10.5) \mathrm{SV}$ by Whitworth and Peterson (1985);

- in the Crozet-Kerguelen area: 118 SV by Gamberoni et al. (1982).

A fluctuation of occanic zonal transport of one Sverdrup $\left(1 \mathrm{SV}=10^{6} \mathrm{~m}^{3} / \mathrm{s}\right.$ of water $\left.=10^{9} \mathrm{~kg} / \mathrm{s}\right)$ at $45^{\circ}$ latitude could be expressed in 1.o.d. changes by one microsecond. So the real mean ratio $<\mathrm{Mo} / \mathrm{Ma}>$ is about $120 / 2300=5.2 \%$, which is close to our own estimate $(5 \%)$.

Then again, fluctuations of $\mathrm{Ma}$ expressed in change of 1.o.d. have amplitudes of the order of \pm 0.5 milliseconds (Rosen, Salstein, 1983); with the same reasoning, we can estimate that fluctuations of the Antarctic Circumpolar Current will be $25 \mathrm{~Sv}$ : measurements through the Drake Passage show fluctuations of the order of $30 \mathrm{~Sv}$ (Pillsbury et al., 1979; Wearn, Baker, 1980; Whitworth, Peterson, 1985).

Modelling the Antarctic Circumpolar Current in the future could help in understanding its effect on earth rotation fluctuations; but the angular momentum transfer process between the solid earth and the oceans ( $70 \%$ of the earth surface) remains an unsolved problem. Therefore we have to distinguish the role of wind driven currents-related to wind-stress-and the role of oceanic free waves-related to long wave propagation. 
The following paragraph provides a brief review of long oceanic free waves on a planetary scale and on their possible influence on l.o.d. changes.

\section{CHARACTERISTICS OF LONG OCEANIC FREE WAVES ON A PLANETARY SCALE}

The world ocean is stratified in density and oceanographers distinguish "barotropic" from "baroclinic" modes for waves in the ocean. The term "barotropic" means that the pressure is constant on surfaces of constant water density, the word "baroclinic" means that pressure is not constant on these density surfaces. It is now conventional to describe as of "barotropic mode", the surface gravity wave, even if this is not exactly true for the real ocean, but only for a fluid of uniform density: the phase-speed "c" of long surface gravity waves is related to the gravity $\mathrm{g}$ and the depth $\mathrm{H}$ of the ocean: $\mathrm{c}=\sqrt{(\mathrm{gH})}$. With $\mathrm{g}=10 \mathrm{~m} / \mathrm{s}^{2}$, a typical value for $\mathrm{c}$ is $200 \mathrm{~m} / \mathrm{s}$ in a $4000 \mathrm{~m}$ deep ocean.

\section{The "barotropic" mode}

Let us consider the "homogeneous" ocean and a surface wave of the form: $n=\mathrm{A} \cos (k x+l y-\sigma t)$ where $n$ is the displacement of the sea level from the rest position, $\mathrm{K}(\mathrm{k}, 1)$ the horizontal wave number vector, $x$ the coordinate in longitude, $y$ the coordinate in latitude, $\sigma$ the frequency and $t$ the time.

\section{Long gravity waves}

Tidal forces, atmospheric systems (wind-stress and atmospheric pressure fields) generate important effects on the sea level at coastal boundaries (i.e. tides, storm surges, Kelvin waves...). Although storm surges could have tremendous consequences at the coast, their influences occur on an area of several thousands of $\mathrm{km}^{2}$, negligible on a global scale; only oceanic tides could significantly contribute to l.o.d. changes (Dickman, 1983; Baader et al., 1983). The sea-level response depends on the ratio of speeds of progress of equilibrium tides around the earth compared with the long gravity speed "c". The fortnightly tide would be close to equilibrium, but this is not true for diurnal and semi-diurnal tides which move around the earth once per day, giving a speed of $350 \mathrm{~m} / \mathrm{s}$, nearly twice as fast as the long-wave speed c (circa $200 \mathrm{~m} / \mathrm{s}$ or $20000 \mathrm{~km} /$ day). Nevertheless free waves play an important role in the description of the tides: for instance the Kelvin wave parts are a major element of tides in the Pacific. Tidal components of earth-rotation parameters are well documented and are discussed with solid tides (Melchior, 1985).

\section{Planetary waves}

Planetary or Rossby waves are quasi-geostrophic and are determined by the "beta" effect $(\beta=\mathrm{df} / \mathrm{dy}$; $\mathrm{f}$, Coriolis parameter). Their phase-speed is derived from the dispersion equation:
$\mathrm{C}=\sigma / k=-\beta /\left(k^{2}+l^{2}+f^{2} / c^{2}\right)$ showing that all planetary waves have westward propagation. The ratio $R$ of the kinetic energy density over potential energy density (averaged over a wave length) is given by $R=(\mathrm{Ka})^{2}$ where $\mathrm{K}$ is the horizontal wave number vector already defined $\left(\mathrm{K}^{2}=k^{2}+l^{2}\right)$ and "a" the Rossby radius $(a=c / f)$. Typical values for oceans are: $\mathrm{H}=4000 \mathrm{~m}$, $\mathrm{c}=200 \mathrm{~m} / \mathrm{s}, \mathrm{a}=2000 \mathrm{~km}$. It follows that we can distinguish:

$-\mathbf{R}<<1$ : barotropic planetary waves would have most of their energy in the potential form for scales larger than the Rossby radius "a", with westward propagation: $C \approx-\beta a^{2}=-80 \mathrm{~m} / \mathrm{s}=-8000 \mathrm{~km} /$ day. Because of the scale dimension, these waves which are non dispersive, are difficult to generate in the real ocean on our earth planet; the wave length has to be of the order of $\mathrm{L}=2 \pi \mathrm{a}=12500 \mathrm{~km}$ which is the dimension of the Pacific Ocean.

$-\mathrm{R}>>1$ : atmospheric systems which have northsouth scales of circa $\delta y=1000 \mathrm{~km}$ (smaller than the oceanic barotropic Rossby radius $a=2000 \mathrm{~km}$ ) can produce in the oceans short barotropic waves which are dispersive and whose energy is mainly kinetic; they propagate westward with phase speeds of the order of $\mathrm{C} \approx-\beta / l^{2}=-20 \mathrm{~m} / \mathrm{s}=2000 \mathrm{~km} /$ day.

The Southern Ocean is the only one which could be concerned with a strong atmospheric input all around the world on $20000 \mathrm{~km}$; the barotropic adjustment time would be about: $T=(20000 \mathrm{~km}) /(2000 \mathrm{~km} /$ day $)$ $=10$ days. But fluctuations of the Antarctic Circumpolar Current, which amount to about 30 Sverdrups, are mainly related to variations of the total wind-stress all over the Southern Ocean (Wearn, Baker, 1980). These authors set up a time lag of 7 days, over which fluctuations of the total wind-stress on the AACC have a maximum of correlation with oceanic transport changes in the Drake Passage. We shall return to this time lag, which seems too short to be attributed to barotropic adjustment, in the discussion.

In summary, for oceanic barotropic modes, ocean dynamics give large wave phase-velocities ranging from 2000 to $20000 \mathrm{~km} /$ day; if any influence could be exerted on the earth-rotation parameters by oceanic barotropic waves, this would be in the frequency band ranging from 1 to $1 / 10$ cycle-per-day with a significant phase lag. The actual sampling of earth rotation parameters ( 1 every 5 days for long series) does not permit the study of this frequency domain; but, except for tidal frequencies, we cannot expect any discernible influence from these oceanic waves on earth-rotation parameters.

\section{The "baroclinic" modes}

The linearized theory of ocean dynamics gives for the long "baroclinic" waves similar results to the barotropic ones; the depth " $H$ " of the homogeneous ocean has to be replaced by an equivalent depth "He" for each baroclinic mode. For the first baroclinic mode (the more important in the oceans), typical values for phase velocities (c) are 2 to $3 \mathrm{~m} / \mathrm{s}$, corresponding to an equivalent depth $\mathrm{He}$ of 0.5 to $1 \mathrm{~m}$. 
The baroclinic Rossby radius (a) would be of $30 \mathrm{~km}$. Westward phase speeds (C) of long baroclinic planetary waves are a function of latitude: about $2.5 \mathrm{~cm} / \mathrm{s}$ at $30^{\circ}$ latitude, this speed reaches $50 \mathrm{~cm} / \mathrm{s}$ at the equator for the first mode. This explains why baroclinic adjustments in the ocean are made on a time scale of several years at middle and high latitudes and of a few months in the equatorial belt.

Although these baroclinic modes could be responsible for strong currents in surface layers above the main and seasonal thermoclines, the vertical integrated current is zero and has no effect on the oceanic angular momentum variations. Moreover, in "baroclinic" mode, the bottom pressure does not change and these oceanic waves could not make any contribution to the loading of the earth by the oceans.

OCEAN-ATMOSPHERE COUPLING; THE GLOBAL WATER MASS EXCHANGE

The ocean-atmosphere coupling is governed not only by momentum transfers, but also by thermodynamic processes: the water mass exchange, through the cycle: evaporation, condensation, precipitation, concerns a mean global evaporation of about $1000 \mathrm{~mm} / \mathrm{year}$, compensated by an equivalent amount of global precipitation (Baumgartner, Reichel, 1975). The scheme of the global water cycle is quite simple; evaporation and precipitation over the global ocean are more important than over the land. Nevertheless, over the oceans, total evaporation exceeds total precipitation; the difference is compensated by run-off from the continents where, on the average, precipitation exceeds evaporation. The mean run-off is estimated as $1.2 \mathrm{SV}$ $=0.4 \times 10^{14} \mathrm{~m}^{3} /$ year, that means (on an annual scale) an excess of evaporation over precipitation of $10 \mathrm{~cm}$ over the oceans ( 360 million $\mathrm{km}^{2}$ ) and an excess of precipitation over evaporation of $24 \mathrm{~cm}$ over land (150 million $\mathrm{km}^{2}$ ).

According to Bryan and Oort (1984), the global water balance, computed from aerological data covering the period ranging May 1963-April 1973, has a strong seasonal cycle. During the northern autumn (September, October, December), global precipitation exceeds total evaporation; the situation is reversed during the other 9 months. But the annual total run-off, estimated by Bryan and Oort, shows a discrepancy by a factor 5 from Baumgartner and Reichel's results which are in good agreement with 1979 data (First GARP Global Experiment: FGGE). Nevertheless, if we consider that the ratio values of seasonal fluctuations/annual mean run-off are correct in Bryan and Oort's paper, the oceans would lose about $1.5 \mathrm{~cm}$ of water from January to August. According to Trenberth (1981), this amplitude would be of $0.4 \mathrm{~cm}$ only.

A discussion on errors introduced in l.o.d. change calculations by accounting for the static contribution of water before precipitation, but not after, can be found in the appendix to Eubanks et al. (1985). Unfortunately, these authors could not include this effect in their analysis because spherical harmonics $\left(\mathrm{J}_{0}\right.$ and $\left.\mathrm{J}_{2}\right)$ of the atmospheric surface pressure field are not currently performed by national data centres.

Nevertheless, because the dynamics of the global atmosphere is closely related to the air-sea interaction within the process of evaporation and precipitation, we can notice the following relationships between l.o.d. and strong convection phenomena in the atmosphere:

- in the annual cycle, the earth-rotation velocity is maximum in July-August when the total amount of water released by the oceans is maximum; on the other hand, the maximum of water is present in the solid earth (oceans included) during the northern winter when the l.o.d. is maximum (minimum of the earth rotation velocity);

- strong intertropical convections over the Indian and Pacific Oceans is the motor of the $30-60$ days atmospheric oscillations which closely related to about 0.2 millisecond fluctuations of earth-rotation (Whyshall, Hide, 1985; Weickmann, 1983).

The study of these relationships could be a topic for further research on the role of the water cycle on the process of the angular momentum transfer between the solid earth and the atmosphere. A global uniform evaporation of $1 \mathrm{~cm}$ of water which is then condensed on the polar sheets (e.g. on the 14 million $\mathrm{km}^{2}$ of Antarctica) could shorten the 1.o.d. by about 0.18 milliseconds. This process could have more influence than the mean flux of the AACC ( $120 \mathrm{SV} \approx 0.12$ milliseconds on l.o.d. change).

\section{DISCUSSION AND CONCLUSION}

We have reviewed the possible influence of the oceans on earth-rotation.

- Phase velocities of free oceanic barotropic waves (long gravity and Rossby waves) range between 2000 to $20000 \mathrm{~km} /$ day: these waves could act on $1.0 . d$. changes in a frequency band ranging from 0.1 to 1 cycle per day. Only oceanic waves resulting from tidal forces can leave their signature on l.o.d. changes in this frequency band.

- On the seasonal and interannual scales, two major contributions of the oceans could be the dynamics of the Southern Ocean and global water mass balance fluctuations:

- The dynamics of the Southern Ocean could contribute, as an upper bound, to $5 \%$ of 1. o.d. changes on the seasonal and annual scales; but, because the Southern Ocean is wind-driven (friction effect), the time lag between the total wind stress and the oceanic transport would be about 7 days. No such time lag has been observed in cross-correlation between 1.o.d. change and atmospheric momentum fluctuations: oceanic friction could not be the main process for momentum transfer from the atmosphere to the earth and vice versa. 
Brosche and Sündermann (1985) have estimated the phase and the amplitude of the angular momentum which is stored in the AACC and these values are confronted with Eubank et al.'s computations (1984), giving phase lag larger than 10 days; this comparison should be revised with respect to the contribution of stratospheric wind fluctuations in atmospheric angular momentum (Rosen, Salstein, 1985) which are not included in the angular momentum budget from Eubank et al. (1984). Wind-stress on dry land or atmospheric pressure gradients across mountain ranges could act on 1.o.d. changes with a shorter time lag; these two mecanisms must certainly have a greater influence than oceanic friction.

Spatial sampling deficiencies and bad accuracy of aerological data preclude the computation of reliable quantitative estimates of parameters required in the global water balance; peculiarly, it is quite hard to measure interannual and seasonal variations of total water in the atmosphere. But from rough estimations it is clear that the latitudinal exchange of water between ocean and atmosphere cannot be neglected and could have more influence on 1.o.d. changes than the zonal flux fluctuations of the Southern Ocean. The importance of seasonal and interannual water mass balance as a detectable geophysical cause in earth-rotation parameters should be more accurately investigated in future studies.

\section{Acknowledgements}

Dr. O. Talagrand from the Laboratoire de Météorologie Dynamique (Paris) and anonymous reviewers made helpful comments on an earlier version.

\section{REFERENCES}

Baader H. R., Brosche P., Hövel W., 1983. Ocean tides and periodic variations of the earth rotation, $J$. Geophys., 52, 140-142.

Barnes R. T. H., Hide R., White A. A., Wilson C. A., 1983. Atmospheric angular momentum fluctuations, length-of-day changes and polar motions, Proc. R. Soc. Lond., A 387, 31-73.

Baumgartner A., Reichel E., 1975. The world water balance, Elsevier, New York, $127 \mathrm{p}$.

Brosche P., Sündermann J., 1985. The Antarctic circumpolar current and its influence on the earth's rotation, Dtsch. Hydrogr. Z., 38, 1, $1-6$.

Bryan F., Oort A., 1984. Seasonal variation of the global water balance based on aerological data, J. Geophys. Res., 80, D7, 1171711730 .

Dickman S. C., 1983. The rotation of the ocean-solid earth system, J. Geophys. Res., 88, 6373-6394.

Eubanks T. M., 1985. E1 Niño type oceanic effects on earth rotation, Proc. Nato Adv. Res. Workshop, Bonas, June 1985, France.

Eubank T.M., Dickey J. O., Steppe J. A., 1984. The geophysical significance of systematic errors in the earth's angular momentum budget, JPL Geod. Geophys. Rep., 106, 21 p.

Eubanks T.M., Steppe J. A., Dickey J.O., Callahan P.S., 1985. A spectral analysis of the earth's angular momentum budget, $J$. Geophys. Res., 90, B7, 5385-5404.

Gamberoni L., Geronimi J., Jeannin P.F., Murail J. F., 1982. Study of frontal zones in the Crozet-Kerguelen region, Oceanol. Acta, 5 , 3, 289-299.

Lambeck K., 1980. The earth's variable rotation, geophysical causes and consequences, Cambridge University Press, Cambridge, 449 p.
Melchior P., 1985. Earth rotation and solid tides, Proc. Nato Adv. Res. Workshop, Bonas, June 1985, France.

Munk H.H., Macdonald G.J.F., 1960. The rotation of the earth, Cambridge University Press, Cambridge, 329 p.

Nowlin W.D. Jr., Whitworth III T., Pillsbury R.D., 1977. Structure and transport of the Antarctic circumpolar currents at Drake Passage from short-term measurements, J. Phys. Oceanogr., 7, 788-802.

Pillsbury R. D., Whitworth III T., Nowlin W.D. Jr., Sciremammano F. Jr., 1979. Currents and temperatures as observed in Drake Passage during 1975, J. Phys. Oceanogr., 9, 469-482.

Rosen R. D., Salstein D. A., 1983. Variations in atmospheric angular momentum on global and regional scales and the length-of-day, $J$. Geophys. Res., 88, C9, 5451-5470.

Rosen R. D., Salstein D. A., 1985. Contribution of stratospheric winds to annual and semiannual fluctuations in atmospheric angular momentum and the length of day, J. Geophys. Res., 90, D5, 80338041.

Trenberth K.V., 1981. Seasonal variations in global sea level pressure and the total mass of the atmosphere, J. Geophys. Res., 86, C6, 5238-5246.

Wearn R. B. Jr., Baker D. J. Jr., 1980. Bottom pressure measurements across the Antarctic circumpolar current and their relation to the wind, Deep-Sea Res., 27A, 875-888.

Weickmann K. M., 1983. Intraseasonal circulation and outgoing long wave radiation modes during Northern hemisphere winter, Month. Weath. Rev., 111, 1838-1858.

Whysall K., Hide R., 1984. A seven week fluctuation of the general circulation of the earth's atmosphere: a brief survey, UK Meteorological Office, Tech. Mem. $\mathrm{n}^{\circ} 0218402$. 